\title{
Does second-look endoscopy reduce the bleeding after gastric endoscopic submucosal dissection for patients receiving antithrombotic therapy?
}

Takeshi Uozumi* Det, Tetsuya Sumiyoshi, Yusuke Tomita, Kaho Tokuchi, Hiroya Sakano, Masahiro Yoshida, Ryoji Fujii, Takeyoshi Minagawa, Yutaka Okagawa, Kotaro Morita, Kei Yane, Hideyuki Ihara, Michiaki Hirayama and Hitoshi Kondo

\begin{abstract}
Background: In patients with average risk of bleeding, second-look endoscopy does not reportedly reduce bleeding after gastric endoscopic submucosal dissection. However, effectiveness of second-look endoscopy for patients with a high risk of bleeding, such as those who are taking antithrombotic agents, is unclear. Hence, this study aims to clarify the effectiveness of second-look endoscopy for patients with antithrombotic therapy.

Methods: We studied 142 consecutive patients with 173 gastric epithelial neoplasms who were routinely taking antithrombotic agents and were treated by endoscopic submucosal dissection at Tonan Hospital between November 2013 and December 2019. They were classified into two groups: those with second-look endoscopy (SLE group, 69 patients with 85 lesions) and those without second-look endoscopy (non-SLE group, 73 patients with 88 lesions). The incidence of post-endoscopic submucosal dissection bleeding was compared between the SLE and non-SLE groups.

Results: There were no statistical differences in the rate of patients undergoing single antiplatelet therapy, single anticoagulant therapy, and multiple therapy between the SLE and non-SLE groups (SLE group vs. non-SLE group; 32 [46.4\%], 16 [23.2\%], and 21 [30.4\%] patients vs. 37 [50.7\%], 20 [27.4\%], and 16 [21.9\%] patients, respectively; $p=$ 0.50). Post-endoscopic submucosal dissection bleeding incidence was $21.7 \%(15 / 69)$ and $21.9 \%(16 / 73)$ in the SLE and non-SLE groups, respectively, and did not significantly differ between the two groups $(p=0.98)$.
\end{abstract}

Conclusions: For patients taking antithrombotic agents, the incidence of post-endoscopic submucosal dissection bleeding was not reduced by second-look endoscopy.

Keywords: Antithrombotic agents, Endoscopic submucosal dissection, Second-look endoscopy

\footnotetext{
* Correspondence: uozumitakeshi@gmail.com

Department of Gastroenterology, Tonan Hospital, Kita 4, Nishi 7, Chuo-ku,

Sapporo, Hokkaido 060-0004, Japan
}

(c) The Author(s). 2021 Open Access This article is licensed under a Creative Commons Attribution 4.0 International License, which permits use, sharing, adaptation, distribution and reproduction in any medium or format, as long as you give appropriate credit to the original author(s) and the source, provide a link to the Creative Commons licence, and indicate if changes were made. The images or other third party material in this article are included in the article's Creative Commons licence, unless indicated otherwise in a credit line to the material. If material is not included in the article's Creative Commons licence and your intended use is not permitted by statutory regulation or exceeds the permitted use, you will need to obtain permission directly from the copyright holder. To view a copy of this licence, visit http://creativecommons.org/licenses/by/4.0/ The Creative Commons Public Domain Dedication waiver (http://creativecommons.org/publicdomain/zero/1.0/) applies to the data made available in this article, unless otherwise stated in a credit line to the data. 


\section{Background}

Endoscopic submucosal dissection (ESD) has been the outstanding treatment for gastric epithelial neoplasms with a negligible risk of lymph node metastasis $[1,2]$. However, the procedure can cause the formation of large iatrogenic ulcers, and it sometimes leads to problematic complications, such as bleeding and perforation [3]. Although the administration of proton pump inhibitor (PPI) and prophylactic coagulation after ESD were reportedly effective for preventing post-ESD bleeding [4-7], the incidence of bleeding after gastric ESD remains approximately 5\%. Antithrombotic agents were reported as one of the risk factors for bleeding after gastric ESD, and the incidence of bleeding after gastric ESD for patients taking antithrombotic agents is higher (6.7$31.3 \%)$ than that in those who do not use them [810]. Bleeding after ESD may result in serious events, such as hypovolemic shock; thus, it is important to prevent it.

According to previous studies, rebleeding in patients with hemorrhagic peptic ulcer can be prevented by second-look endoscopy (SLE) after endoscopic hemostasis $[11,12]$. Based on such studies, SLE was empirically performed after gastric ESD in many institutions [13]. However, three randomized controlled trials (RCTs) reported that routine SLE did not reduce bleeding after gastric ESD in patients with average risk of bleeding [14-16]. Among these RCTs, the SAFE trial, which was a Japanese multicenter prospective RCT, excluded patients with high risk of bleeding such as those who underwent antithrombotic therapy [14]. In the other two RCTs, the details of the antithrombotic agents were not described $[15,16]$. Thus, to our knowledge, no studies have ever reported on the effectiveness of SLE for patients taking antithrombotic agents and the effectiveness of SLE is unclear.

In this study, we aimed to retrospectively assess whether SLE reduces bleeding after ESD in patients with high risk of bleeding, particularly focusing on those taking antithrombotic agents.

\section{Methods}

\section{Patient selection}

Medical records of patients who underwent ESD for gastric epithelial neoplasms, including early gastric cancers and adenomas, were retrospectively reviewed at Tonan Hospital from November 2013 to December 2019. These data included patient characteristics, endoscopic images, clinicopathological features, histopathological reports, and post-ESD complications. A total of 830 consecutive patients with 1006 gastric epithelial neoplasms underwent ESD. Among these patients, those with lesions arising from remnant stomach $(n=30)$ or gastric tube $(n=9)$, without antithrombotic therapy $(n=647)$, and with perforation during procedure $(n=2)$ were excluded from the study. Finally, 142 consecutive patients with 173 lesions, who were taking antithrombotic agents, were enrolled in this study (Fig. 1). SLE was empirically performed for all patients in our hospital; however, since January 2017, routine SLE was ceased in principle for all the patients including those with a high risk of bleeding after getting informed consent from them. These 142 patients were classified into the following two groups: SLE group (69 patients with 85 lesions) and non-SLE group (73 patients with 88 lesions). Prior to treatment, either the

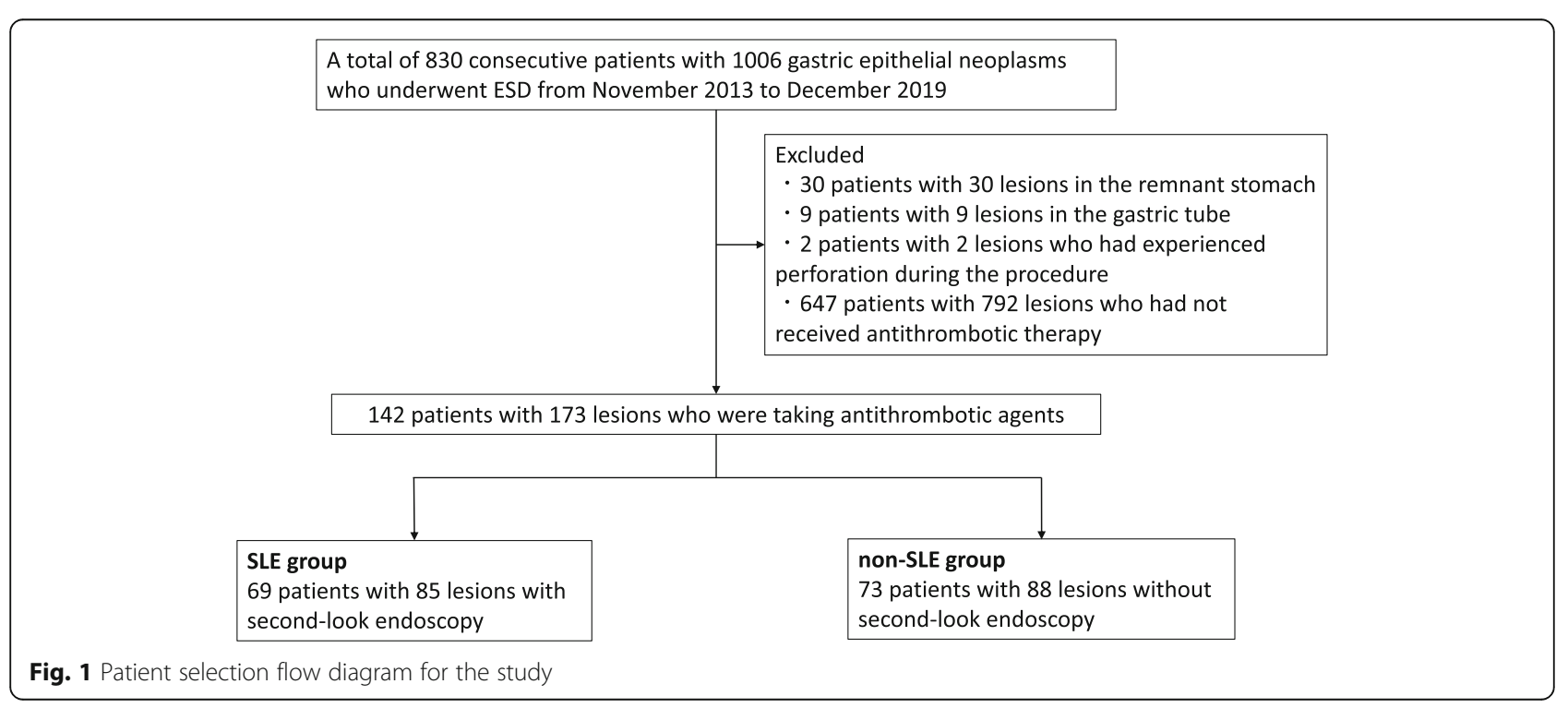


patient or their family provided written informed consents, and the study protocol was approved by the Institutional Review Board of Tonan Hospital and conducted in accordance with the Declaration of Helsinki.

\section{Patients}

Data on patient characteristics, including age, sex, hypertension, diabetes, hyperlipidemia, ischemic heart disease, cerebrovascular disease, chronic kidney disease, treatment with antithrombotic agents, regular use of non-steroid anti-inflammatory drugs (NSAIDs), and treatment with gastric acid blockers, were collected. Antithrombic agents were classified as antiplatelet agents (aspirin, cilostazol, and thienopyridine) and anticoagulants (warfarin and direct oral anticoagulants [DOACs]). Gastric acid blockers were either PPIs or potassium-competitive acid blockers. The risk of post-ESD bleeding was evaluated for all patients according to the BEST-J score, which is a novel scoring system used to predict post-ESD bleeding in gastric epithelial neoplasms [17]. The risk of post-ESD bleeding was scored based on patient and lesion characteristics, and the total score was categorized as either low risk (post-ESD bleeding risk was $2.8 \%$ ), intermediate risk (6.1\%), high risk (11.4\%), or very high risk (29.7\%).

\section{Indications for ESD and ESD procedure}

The indication for ESD included gastric adenoma and early gastric cancer that clinically fulfilled the absolute or expanded indication criteria according to the Japanese Gastric Cancer Treatment Guidelines of 2014 [18].

ESD was performed based on a standard procedure with a single-channel (GIF-Q260J; Olympus Medical Science) or a two-channel (GIF-2TQ260M; Olympus Medical Science) endoscope. In short, marking was made on the normal mucosa approximately $5 \mathrm{~mm}$ from the tumor margin. To lift the lesion, hyaluronic acid mixed with $10 \%$ glycerin solution in a $1: 3$ ratio with a small amount of epinephrine and indigo carmine was injected into the submucosal layer. After an initial incision was made using a needle knife (KD-1 L-1; Olympus Medical Science), an insulationtipped knife 2 (KD-611 L; Olympus Medical Science) was used for making the circumferential incision and submucosal dissection. Intraoperatively, Coagrasper (FD-410LR; Olympus Medical Science) in soft coagulation mode was used to control bleeding. After completion of the ESD procedure, all exposed vessels on the iatrogenic ulcers were also coagulated using the Coagrasper in soft coagulation mode. All electrosurgical devices were used with an electrosurgical generator (VIO 300D; Erbe Elektromedizin). Based on the Japanese classification of gastric carcinoma, the resected specimens were examined pathologically with regard to tumor size, histological type, depth of invasion, lymphovascular invasion, and tumor involvement along the lateral and vertical margins [19].

\section{SLE}

In this study, SLE was defined as a scheduled endoscopy that was performed on the day after ESD regardless of any suspicion of post-ESD bleeding. If the exposed vessels and/or active bleeding were observed on the postESD ulcer during SLE, hemostasis was performed with the Coagrasper in soft coagulation mode until they were sufficiently treated.

\section{Perioperative managements}

Although $20 \mathrm{mg}$ of esomeprazole was traditionally administered from the day of ESD to 8 weeks after the procedure, from August 2015, vonoprazan was administered from the day of ESD to 2 weeks after the procedure and then was switched to esomeprazole until 8 weeks after the ESD. The general condition of all patients was assessed via physical examination (including blood tests) the day after ESD; in the SLE group, the findings obtained during SLE were also assessed. The patients started drinking water on the day after ESD and resumed eating a soft diet 2 days after the procedure unless there were signs of ESD-related complications, such as perforation and post-ESD bleeding. Thereafter, the patients were discharged approximately on postoperative day 7 according to our clinical pathway.

\section{Management of antithrombotic agents}

After confirming with the prescribing physician whether treatment with antithrombotic agents could be interrupted or not, ESD was performed in accordance with the Japanese Gastroenterological Endoscopy Society guideline [20]. Heparin replacement was done for patients taking antithrombotic agents until December 2016 at the physician's discretion in accordance with the guideline. Since January 2017, heparin replacement was ceased for all patients and ESD was performed after the prothrombin time international normalized ratio (PT-INR) was confirmed to be within the therapeutic range when warfarin administration was continued. DOACs were continued until the day prior to ESD and ceased on the morning of ESD. When treatment with antithrombotic agents was interrupted, antithrombotic therapy was restarted the day after ESD in the non- 
SLE group and after the confirmation of no postESD bleeding during SLE in the SLE group.

Based on a previous report, in this study, antithrombotic agent interruption was defined as the cessation of antithrombotic agents including temporary replacement of other antithrombotic agents by heparin, aspirin, or cilostazol [17].

\section{Measured outcome parameters}

Post-ESD bleeding was defined as hemorrhage with clinical symptoms, such as hematemesis, melena, and hemoglobin decrease of $\geq 2 \mathrm{~g} / \mathrm{dL}$ compared to the patient's latest data, which was confirmed by emergency endoscopy within 28 days after ESD, according to a previous report [14]. Subclinical bleeding during SLE was not counted as post-ESD bleeding. Post-ESD bleeding was classified into two phases: early and delayed bleeding. Early bleeding was defined as bleeding diagnosed within $24 \mathrm{~h}$ after ESD and delayed bleeding was defined as bleeding diagnosed later than the period that was defined as early bleeding. To evaluate the benefit of SLE, the incidence of post-ESD and delayed bleeding between the SLE and non-SLE groups were compared. The time-to-event curve for the absence of post-ESD bleeding between the two groups was evaluated. All patients were classified into three groups: single antiplatelet therapy, single anticoagulant therapy, and multiple antithrombotic therapy groups, and postESD bleeding and delayed bleeding rates of these groups were compared. Furthermore, all the patients were classified into four groups according to the BEST-J score: low risk group, intermediate group, high risk group, and very high risk group, and postESD and delayed bleeding rate of these groups were compared. The incidence of adverse events, such as blood transfusion and thromboembolism, was also compared between the SLE and non-SLE groups. The incidence of post-ESD bleeding in patients who received prophylactic coagulation during SLE was also evaluated.

\section{Statistical analysis}

Fisher's exact test, chi-square test, Welch's $t$ test, and student's $t$ test were used to appropriately analyze the significance of differences in the patient characteristics, clinicopathological findings, rate of post-ESD bleeding, rate of delayed bleedings, and rate of adverse events. Post-ESD bleeding rates from the day of procedure were calculated using the Kaplan-Meier method and compared using the log-rank test. A value of $p<0.05$ was considered statistically significant.

\section{Results}

\section{Patients and lesions}

Table 1 shows the clinical characteristics of 142 consecutive patients with gastric epithelial neoplasms resected by ESD. Patients in the SLE group were younger than those in the non-SLE group $(75.7 \pm 7.1$ years vs. $78.2 \pm 6.2$ years; $p=0.02$ ). Sex and comorbidities, including ischemic heart disease, hypertension, diabetes mellitus, hyperlipidemia, cerebrovascular disease, and renal failure, were not significantly different between both groups. No patients received hemodialysis and regular NSAID administration. There were no significant differences in the rate of patients undergoing single antiplatelet therapy, single anticoagulant therapy, and multiple therapy between the SLE and non-SLE groups (SLE group vs. non-SLE group; 32 [46.4\%], 16 [23.2\%], and 21 [30.4\%] patients vs. 37 [50.7\%], 20 [27.4\%], and 16 [21.9\%] patients, respectively; $p=0.50)$. The SLE group had a significantly higher rate of patients experiencing antithrombotic agent interruption than the non-SLE group (55 patients [79.7\%] vs. 41 patients [56.1\%]; $p<0.05)$. Among the patients with interruption of antithrombotic therapy, 12 patients who received heparin replacement and 9 patients who received aspirin or cilostazol replacement were included in the SLE group and 10 patients who received aspirin or cilostazol replacement were included in the non-SLE group. The non-SLE group exhibited a significantly higher administration of vonoprazan than the SLE group (29 patients [42.0\%] in the SLE group vs. 72 patients [98.6\%] in the nonSLE group; $p<0.05)$. There were no statistical differences in the rate of patients who had multiple lesions between the two groups (11 patients [15.9\%] in the SLE group vs. 14 patients $[19.1 \%] ; p=0.61$ ).

Table 2 presents the clinical characteristics of 173 lesions. No statistical differences were found in tumor location, tumor size, macroscopic type, histological type, ulcerative findings, histological depth, procedure time, specimen size, and en bloc resection between the two groups. The SLE group had a significantly lower number of lesions resected by an operator, whose experience was lower than 30 cases, than the non-SLE group (1 lesion [1.2\%] vs. 11 lesions $[11.4 \%] ; p<0.05)$.

As to the risk classification of post-ESD bleeding scored by the BEST-J score, no statistical differences were observed in the low risk, intermediate risk, high risk, and very high risk (SLE group vs. non-SLE group; 11 [15.9\%], 13 [18.8\%], 31 [44.9\%], and 14 [20.3\%] patients vs. 6 [8.2\%], 14 [19.2\%], 37 [50.7\%], and 16 [21.9\%] patients, respectively; $p=0.56$ ) (Table 3). 
Table 1 Characteristics of patients

\begin{tabular}{|c|c|c|c|}
\hline & SLE group $(n=69)$ & Non-SLE group $(n=73)$ & $p$ values \\
\hline Age (SD) (years) & $75.7 \pm 7.1$ & $78.2 \pm 6.2$ & 0.02 \\
\hline Sex (Men/Women) & $60(87.0 \%) / 9(13.0 \%)$ & $60(82.2 \%) / 13(17.8 \%)$ & 0.43 \\
\hline \multicolumn{4}{|l|}{ Comorbidities } \\
\hline Hypertension & $41(59.4 \%)$ & $53(72.6 \%)$ & 0.10 \\
\hline Diabetes mellitus & $17(24.6 \%)$ & $26(35.6 \%)$ & 0.15 \\
\hline Hyperlipidemia & $30(43.5 \%)$ & $35(47.9 \%)$ & 0.59 \\
\hline Ischemic heart disease & $28(40.6 \%)$ & $29(39.7 \%)$ & 0.92 \\
\hline Cerebrovascular disease & $28(40.6 \%)$ & $26(35.6 \%)$ & 0.54 \\
\hline Renal disease $\left(\mathrm{eGFR}<30 \mathrm{~mL} / \mathrm{min} / 1.73 \mathrm{~m}^{2}\right)$ & $1(1.4 \%)$ & $1(1.4 \%)$ & 0.97 \\
\hline Antithrombotic agent & & & 0.50 \\
\hline Single antiplatelets & $32(46.4 \%)$ & $37(50.7 \%)$ & \\
\hline Aspirin & 15 & 20 & \\
\hline Cilostazol & 6 & 5 & \\
\hline Thienopyridine & 11 & 12 & \\
\hline Single anticoagulants & $16(23.2 \%)$ & $20(27.4 \%)$ & \\
\hline Warfarin & 7 & 7 & \\
\hline DOACs & 9 & 13 & \\
\hline Multiple therapy & $21(30.4 \%)$ & $16(21.9 \%)$ & \\
\hline Anticoagulant + antiplatelet & 9 & 7 & \\
\hline DAPT & 10 & 8 & \\
\hline Triplet therapy & 2 & 1 & \\
\hline Interruption of antithrombotic agents & $55(79.7 \%)$ & $41(56.1 \%)$ & $<0.05$ \\
\hline Heparin replacement & 12 & 0 & \\
\hline Aspirin or cilostazol replacement & 9 & 10 & \\
\hline Acid blocker & & & $<0.05$ \\
\hline Esomeprazole & $40(58.0 \%)$ & $1(1.4 \%)$ & \\
\hline Vonoprazan & $29(42.0 \%)$ & $72(98.6 \%)$ & \\
\hline Multiple lesions & $11(15.9 \%)$ & $14(19.1 \%)$ & 0.61 \\
\hline
\end{tabular}

*SD standard deviation, DOACs direct oral anticoagulants, DAPT dual antiplatelet therapy

\section{Post-ESD bleeding and delayed bleeding}

No significant difference was found in the incidence of post-ESD bleeding between the SLE group and non-SLE group (21.7\% [15/69] vs. $21.9 \%$ [16/73]; $p=$ 0.98 ) (Table 4), as well as the incidence of delayed bleeding (20.3\% [14/69] vs. $19.2 \%$ [14/73]; $p=0.87)$. Likewise, the time-to-event curve for the absence of post-ESD bleeding showed no significant difference between the groups (SLE group vs. non-SLE group; 78.3, 95\% CI: $66.6-86.3 \%$ vs. $78.1,95 \%$ CI: $66.7-$ $86.0 \% ; p=0.99$ ) (Fig. 2). Post-ESD bleeding occurred within 2 weeks in 90.3\% [28/31] of patients (Fig. 3). In addition, the incidence of post-ESD bleeding in patients undergoing single antiplatelet therapy $(9.4 \%$ [3/32] vs. $10.8 \%$ [4/37]; $p=0.84)$, single anticoagulant therapy $(6.3 \%[1 / 16]$ vs. $15.0 \%[3 / 20] ; p=0.41)$, and multiple therapy $(52.4 \%[11 / 21]$ vs. $56.2 \%[9 / 16] ; p=$
0.82) was not significantly different between the SLE group and non-SLE group (Table 4); similar findings were obtained for the incidence of delayed bleeding.

The incidence of post-ESD bleeding in the low risk group of the BEST-J score $(9.1 \%$ [1/11] vs. $16.7 \%$ [1/6]; $p=0.64)$, intermediate risk group $(8.3 \%[1 / 13]$ vs. $7.1 \%$ [1/14]; $p=0.96)$, high risk group $(19.4 \%$ [6/31] vs. $21.6 \%$ [8/37]; $p=0.82)$, and very high risk group (50\% [7/14] vs. $37.5 \%[6 / 16] ; p=0.49$ ) was not significantly different between the SLE group and non-SLE group (Table 5); similar findings were obtained for the incidence of delayed bleeding.

Subclinical bleeding was detected and hemostasis was performed in two cases during SLE. Prophylactic coagulation for exposed vessel was performed during SLE in 60patients in the SLE group. In the 62 patients who underwent prophylactic coagulation or 
Table $\mathbf{2}$ Characteristics of lesions

\begin{tabular}{|c|c|c|c|}
\hline & SLE group $(n=85)$ & Non-SLE group $(n=88)$ & $p$ values \\
\hline Tumor location & & & 0.50 \\
\hline Upper & $10(11.8 \%)$ & $13(14.8 \%)$ & \\
\hline Middle & $24(28.2 \%)$ & $30(34.1 \%)$ & \\
\hline Lower & $51(60.0 \%)$ & $45(51.1 \%)$ & \\
\hline Tumor size (mm) (SD) & $15.1 \pm 12.5$ & $15.2 \pm 12.4$ & 0.96 \\
\hline Macroscopic type & & & 0.77 \\
\hline Protruding & $38(44.7 \%)$ & $38(43.1 \%)$ & \\
\hline Flat/depressed & $39(45.9 \%)$ & $44(50.0 \%)$ & \\
\hline Combined & $8(9.4 \%)$ & $6(6.8 \%)$ & \\
\hline Histological type & & & 0.30 \\
\hline Adenoma or differentiated type & $82(96.5 \%)$ & $87(98.9 \%)$ & \\
\hline Undifferentiated type & $3(3.5 \%)$ & $1(1.1 \%)$ & \\
\hline Ulcerative finding & $6(7.1 \%)$ & 7 (8.0\%) & 0.82 \\
\hline Histological depth & & & 0.95 \\
\hline Adenoma/m/SM1 & $79(92.9 \%)$ & $82(93.1 \%)$ & \\
\hline SM2 & $6(7.1 \%)$ & $6(6.8 \%)$ & \\
\hline Procedure time & & & 0.97 \\
\hline$\leq 60 \min$ & $61(71.8 \%)$ & $62(70.4 \%)$ & \\
\hline$>60 \min \leq 120 \min$ & $18(21.2 \%)$ & $20(22.7 \%)$ & \\
\hline$>120 \mathrm{~min}$ & $6(7.1 \%)$ & $6(6.8 \%)$ & \\
\hline Specimen size (mm) (SD) & $41.6 \pm 14.9$ & $42.0 \pm 22.3$ & 0.90 \\
\hline En bloc resection & $85(100 \%)$ & $88(100 \%)$ & \\
\hline Operator experience of $<30$ cases & $1(1.2 \%)$ & $10(11.4 \%)$ & $<0.05$ \\
\hline
\end{tabular}

*SD standard deviation

hemostasis during SLE, the incidence of post-ESD bleeding was $22.6 \%(14 / 62)$ which was similar to that in the non-SLE group.

\section{Adverse events}

The rate of bleeding that required transfusion was also not significantly different between the SLE group and non-SLE group $(10.1 \%$ [7/69] vs. $11.0 \%$ [8/73]; $p=0.87)$. Thromboembolism did not occur in both groups.

\section{Discussion}

Our study revealed that there was no significant difference in the incidence of post-ESD bleeding between the
SLE and the non-SLE groups in patients taking antithrombotic agents.

Although all the patients underwent prophylactic coagulation after ESD completion and 89.8\% (62/69) of patients in the SLE group received additional prophylactic coagulation or hemostasis during SLE, no significant difference was observed in the delayed bleeding rate between the two groups. Mochizuki et al., reported that prophylactic coagulation during SLE did not contribute to the reduction of postESD bleeding in patients with average risk of bleeding [14]. If prophylactic coagulation is adequately performed after ESD completion and a PPI is administered, additional prophylactic coagulation

Table 3 Risk distribution of post-ESD bleeding scored by the BEST-J score

\begin{tabular}{lll}
\hline & SLE group $(\boldsymbol{n}=\mathbf{6 9 )}$ & Non-SLE group $(\boldsymbol{n}=\mathbf{7 3})$ \\
\hline BEST-J score & & \\
Low risk & $11(15.9 \%)$ & $6(8.2 \%)$ \\
Intermediate risk & $13(18.8 \%)$ & $14(19.2 \%)$ \\
High risk & $31(44.9 \%)$ & $37(50.7 \%)$ \\
Very high risk & $14(20.3 \%)$ & $16(21.9 \%)$ \\
\hline
\end{tabular}


Table 4 Details of post-ESD bleeding and delayed bleeding

\begin{tabular}{llll}
\hline & SLE group $(\boldsymbol{n = 6 9 )}$ & Non-SLE group $(\boldsymbol{n}=\mathbf{7 3})$ & $\boldsymbol{p}$ values \\
\hline Post-ESD bleeding & $15 / 69(21.7 \%)$ & $16 / 73(21.9 \%)$ & 0.98 \\
Single antiplatelet & $3 / 32(9.4 \%)$ & $4 / 37(10.8 \%)$ & 0.84 \\
Single anticoagulant & $1 / 16(6.3 \%)$ & $3 / 20(15.0 \%)$ & 0.41 \\
$\quad$ Multiple therapy & $11 / 21(52.4 \%)$ & $9 / 16(56.2 \%)$ & 0.82 \\
Early bleeding & $1 / 69(1.4 \%)$ & $2 / 73(2.7 \%)$ & 0.59 \\
Delayed bleeding & $14 / 69(20.3 \%)$ & $14 / 73(19.2 \%)$ & 0.87 \\
$\quad$ Single antiplatelet & $3 / 32(9.4 \%)$ & $3 / 37(8.1 \%)$ & 0.85 \\
Single anticoagulant & $1 / 16(6.3 \%)$ & $3 / 20(15.0 \%)$ & 0.41 \\
Multiple therapy & $10 / 21(47.6 \%)$ & $8 / 16(50.0 \%)$ & 0.89 \\
\hline
\end{tabular}

during SLE might not contribute to the reduction of post-ESD and delayed bleeding even in patients with high risk of bleeding. Moreover, the discontinuation of SLE after gastric ESD for patients with high risk of bleeding will reduce the economic burden on patients.

In our study, the non-SLE group exhibited a significantly higher administration of vonoprazan than the SLE group. Vonoprazan, a potassium-competitive acid blocker, has a stronger and longer antisecretory effect on
$\mathrm{H}^{+} / \mathrm{K}^{+}$-ATPase than PPI [21]; however, on comparing esomeprazole and vonoprazan, no significant difference was noted in the incidence of post-ESD bleeding [22]. The difference in administration of vonoprazan or esomeprazole may not have affected the result of our study.

The incidence of post-ESD bleeding for patients with antithrombotic agents has been reported to be $6.7-31.3 \%$ [8-10]; these findings were similar those of our study. The reported risk factors for post-ESD

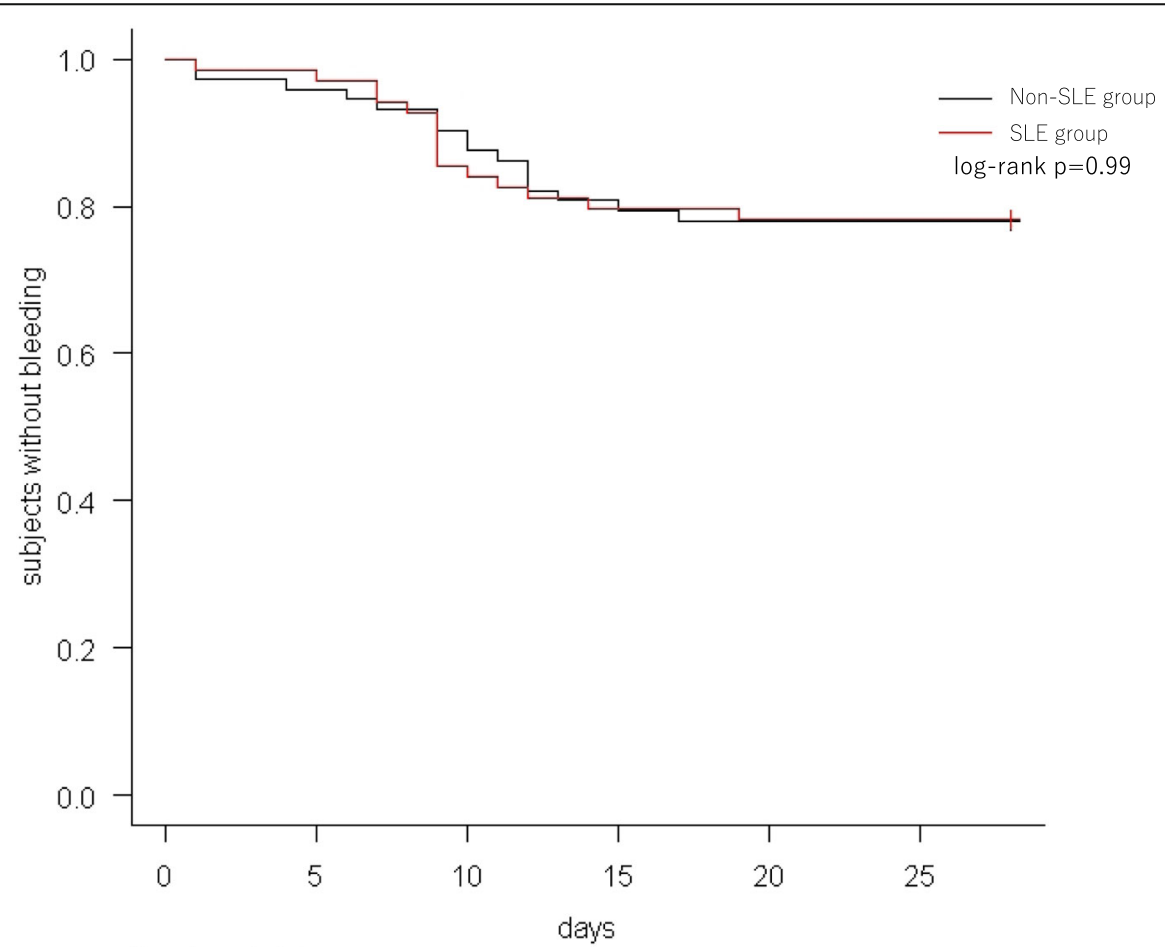

Number at risk

$\begin{array}{lllllll}\text { Non-SLE group } & 73 & 70 & 66 & 59 & 57 & 57 \\ \text { SLE group } & 69 & 68 & 59 & 55 & 54 & 54\end{array}$

Fig. 2 Time-to-event curve of patients without post-ESD bleeding 


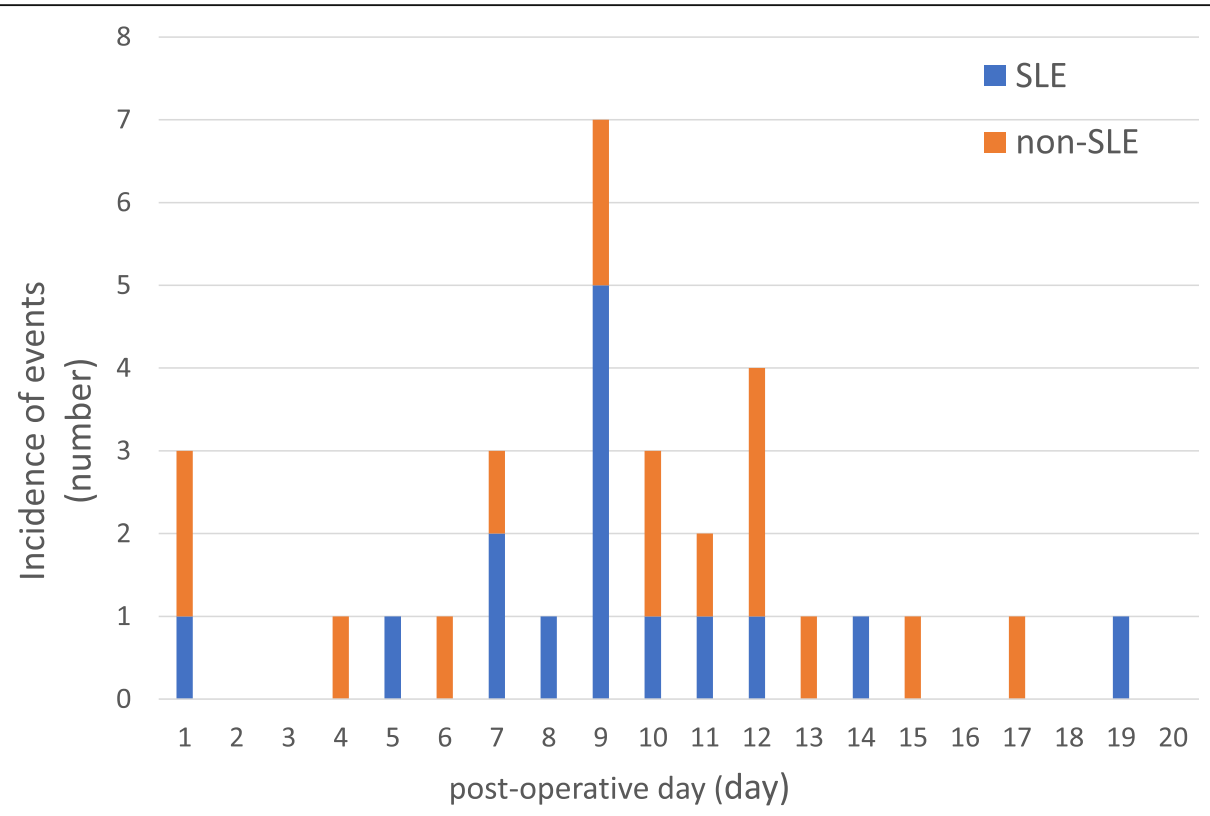

Fig. 3 Timing of post-ESD bleeding

bleeding are tumor size, tumor location, cardiopathy, chronic kidney disease, antithrombotic therapy, multiple antiplatelet therapy, and heparin replacement $[23,24]$. There are several risk factors for post-ESD bleeding, which affect each other; therefore, the risk of post-ESD bleeding should be evaluated for each patient, considering comorbidities, tumor factor, and medication such as antithrombotic agents. Recently, Hatta et al. have reported the BEST-J score [17]. This prediction model consists of patient's comorbidities, tumor factor, and medication, and comprehensively estimates the risk of post-ESD bleeding. There was no statistical difference between the SLE group and non-SLE group in the risk distribution of post-ESD bleeding scored by this prediction model, although the number of patients who underwent heparin replacement was significantly higher in the SLE group than in the nonSLE group. The incidence of post-ESD bleeding and delayed bleeding was not significantly different between the SLE group and non-SLE group regardless of the classification of antithrombotic agents and the risk distribution of the BEST-J score.

SLE might not reduce the incidence of post-ESD bleeding even in patients who received antithrombotic therapy; therefore, other endoscopic approaches are needed. In a nonrandomized control study including patients taking antithrombotic therapy, a tissue-shielding method using polyglycolic acid sheets and fibrin glue showed efficacy in the prevention of post-ESD bleeding (covering group, $5.8 \%$ vs control group, $20.8 \% ; p=0.04$ ) [25]. Recently, Goto et al. have reported that handsuturing method, which is a new technique for closing mucosal defects using absorbable barbed sutures and through-the-scope needle holder, might reduce the risk of post-ESD bleeding even in patients on antithrombotic therapy [26]. These promising methods require advanced endoscopic skills, and widespread adoption of these methods will take time.

This study has some limitations. First, it is a retrospective, single-center study with a small number of cases. Second, there were certain significant differences

Table $\mathbf{5}$ The risk classification of Post-ESD bleeding scored by the BEST-J score

\begin{tabular}{llll}
\hline & SLE group $(\boldsymbol{n}=\mathbf{6 9 )}$ & Non-SLE group $(\boldsymbol{n}=\mathbf{7 3})$ & $\boldsymbol{p}$ value \\
\hline BEST-J score & & & 0.64 \\
Low risk & $1 / 11(9.1 \%)$ & $1 / 6(16.7 \%)$ & 0.96 \\
Intermediate risk & $1 / 13(8.3 \%)$ & $1 / 14(7.1 \%)$ & 0.82 \\
High risk & $6 / 31(19.4 \%)$ & $8 / 37(21.6 \%)$ & 0.49 \\
Very high risk & $7 / 14(50 \%)$ & $6 / 16(37.5 \%)$ & \\
\hline
\end{tabular}


between the SLE and non-SLE groups with regard to patient characteristics and lesions, such as age, PPI administration, operator experience, interruption of antithrombotic therapy, and heparin replacement. Third, the risk of gastrointestinal bleeding varies among different DOACs [27], but the number of patients taking each kind of DOACs was too small to consider the effect of the bleeding. Although our study has these limitations, so far, no other study has estimated the effectiveness of SLE in patients with high risk of bleeding. Therefore, we believe that our study results are meaningful.

\section{Conclusions}

In conclusion, SLE may not reduce the risk of post-ESD bleeding in patients with antithrombotic therapy. We hope that prospective randomized controlled trial will be conducted to clarify the effectiveness of SLE in patients under antithrombotic medication.

\section{Abbreviations}

ESD: Endoscopic submucosal dissection; NSAID: Non-steroid antiinflammatory drugs; PPI: Proton pump inhibitor; RCT: Randomized controlled trial; SLE: Second-look endoscopy; DOAC: Direct oral anticoagulants

\section{Acknowledgements}

Not applicable.

\section{Authors' contributions}

TU and TS conceptualized the study. TU, TS, YT, KT, HS, MY, RF, TM, YO, KM, $\mathrm{KY}, \mathrm{HI}, \mathrm{MH}$, and $\mathrm{HK}$ wrote, reviewed, and edited the manuscript. All authors read and approved the final manuscript.

\section{Funding}

None.

\section{Availability of data and materials}

The datasets used and/or analyzed during the current study are available from the corresponding author on reasonable request.

\section{Declarations}

\section{Ethics approval and consent to participate}

Administrative permissions were not required to access the raw date from Tonan Hospital. The study protocol was approved by the Institutional Review Board of Tonan Hospital and conducted in accordance with the Declaration of Helsinki. Prior to treatment, either the patient or their family provided written informed consent.

\section{Consent for publication}

Not applicable.

\section{Competing interests}

The authors declare that they have no competing interests.

Received: 17 October 2020 Accepted: 12 August 2021

Published online: 23 August 2021

\section{References}

1. Ono H, Kondo H, Gotoda T, Shirao K, Saito D, Hosokawa K, et al. Endoscopic mucosal resection for treatment of early gastric cancer. Gut. 2001;48(2):2259. https://doi.org/10.1136/gut.48.2.225.

2. Isomoto H, Shikuwa S, Yamaguchi N, Fukuda E, Ikeda K, Nishiyama H, et al. Endoscopic submucosal dissection for early gastric cancer: a large-scale feasibility study. Gut. 2009;58(3):331-6. https://doi.org/10.1136/gut.2008.1653 81.
3. Yamamoto Y, Kikuchi D, Nagami Y, Nonaka K, Tsuji Y, Fujimoto A, et al. Management of adverse events related to endoscopic resection of upper gastrointestinal neoplasms: review of the literature and recommendation from experts. Dig Endosc. 2019;31(S1):4-20. https://doi.org/10.1111/den.133 88.

4. Toyokawa T, Inaba T, Omote S, Okamoto A, Miyasaka R, Watanabe K, et al. Risk factors for perforation and delayed bleeding associated with endoscopic submucosal dissection in gastric neoplasms: analysis of 1123 lesions. J Gastroenterol Hepatol. 2012;27(5):907-12. https://doi.org/10.1111/ j.1440-1746.2011.07039.x.

5. Suzuki H, Takizawa K, Hirasawa T, Takeuchi Y, Ishido K, Hoteya S, et al. Shortterm outcomes of multicenter prospective cohort study of gastric endoscopic resection: 'real-world evidence' in Japan. Dig Endosc. 2019:31(1): 30-9. https://doi.org/10.1111/den.13246.

6. Takizawa K, Oda I, Gotoda T, Yokoi C, Matsuda T, Saito Y, et al. Routine coagulation of visible vessels may prevent delayed bleeding after endoscopic submucosal dissection-an analysis of risk factors. Endoscopy. 2008;40(03):179-83. https://doi.org/10.1055/s-2007-995530.

7. Uedo N, Takeuchi Y, Yamada T, Ishihara R, Ogiyama H, Yamamoto S, et al. Effect of a proton pump inhibitor or an $\mathrm{H}$ 2-receptor antagonist on prevention of bleeding from ulcer after endoscopic submucosal dissection of early gastric cancer: a prospective randomized controlled trial. Am J Gastroenterol. 2007;102(8):1610-6. https://doi.org/10.1111/j.1572-0241.2007. 01197.x.

8. Seol S, Ji YA, Nayoung K, Hee KN, Kee WJ, Jeong HL, et al. Comparison of the effects of antithrombotic therapy on delayed bleeding after gastric endoscopic resection: a propensity score-matched case-control study. Gastrointest Endosc. 2019:89:277-85.

9. Gotoda T, Hori K, Iwamuro M, Kono Y, Miura K, Kanzaki H, et al. Evaluation of the bleeding risk with various antithrombotic therapies after gastric endoscopic submucosal dissection. Endosc Int Open. 2017;5(7):E653-62. https://doi.org/10.1055/s-0043-110050.

10. Furuhata T, Kaise M, Hoteya S, lizuka T, Yamada A, Nomura K, et al. Postoperative bleeding after gastric endoscopic submucosal dissection in patients receiving antithrombotic therapy. Gastric Cancer. 2017;20(1):207-14. https://doi.org/10.1007/s10120-015-0588-7.

11. Saeed ZA, Cole RA, Ramirez FC, Schneider FE, Hepps KS, Graham DY. Endoscopic retreatment after successful initial hemostasis prevent ulcer rebleeding: a prospective and randomized trial. Endoscopy. 1996;28(03): 288-94. https://doi.org/10.1055/s-2007-1005455.

12. Chiu PWY, Lam CYW, Lee SW, Kwong KH, Lam SH, Lee DTY, et al. Effect of scheduled second therapeutic endoscopy on peptic ulcer rebleeding: a prospective randomized trial. Gut. 2003;52(10):1403-7. https://doi.org/10.113 6/gut.52.10.1403.

13. Goto O, Fujisiro M, Oda I, Kakushima N, Yamamoto Y, Tsuji Y, et al. A multicenter survey of the management after gastric endoscopic submucosal dissection related to postoperative bleeding. Dig Dis Sci. 2012; 57(2):435-9. https://doi.org/10.1007/s10620-011-1886-5.

14. Mochizuki S, Uedo N, Oda I, Kaneko K, Yamamoto Y, Yamashina T, et al. Scheduled second-look endoscopy is not recommended after endoscopic submucosal dissection for gastric neoplasm (the SAFE trial): a multicenter prospective randomized controlled non-inferiority trial. Gut. 2015;64(3):397405. https://doi.org/10.1136/gutjnl-2014-307552.

15. Ryu HY, Kim JW, Kim HS, Park HJ, Jeon HK, Park SY, et al. Second-look endoscopy is not associated with better clinical outcomes after gastric endoscopic submucosal dissection: a prospective, randomized, clinical trial analyzed on an as-treated basis. Gastrointest Endosc. 2013;78(2):285-94. https://doi.org/10.1016/j.gie.2013.02.008.

16. Kim JS, Chung MW, Chung CY, Paek HC, Ryang DY, Myung DS, et al. The need for second-look endoscopy to prevent delayed bleeding after endoscopic submucosal dissection for gastric neoplasms. Gut Liver. 2014; 8(5):480-6. https://doi.org/10.5009/gnl13226.

17. Hatta W, Tsuji Y, Yoshiki T, Kakushima N, Hoteya S, Doyama H, et al. Prediction model of bleeding after endoscopic submucosal dissection for early gastric cancer: BEST-J score. Gut. 2020;70(3):476-84. https://doi.org/1 0.1136/gutjnl-2019-319926.

18. Japanese Gastric Cancer Association. Japanese gastric cancer treatment guidelines 2014(ver.4). Gastric Cancer. 2017;20(1):1-19. https://doi.org/10.1 007/s10120-016-0622-4.

19. Japanese Gastric Cancer Association. Japanese classification of gastric carcinoma. 3rd English edition. Gastric Cancer. 2011;14:101-12. 
20. Fujimoto K, Fujishiro M, Kato M, Higuchi K, Iwakiri R, Sakamoto C, et al. Guidelines for gastroenterological endoscopy in patients undergoing antithrombotic treatment. Dig Endosc. 2014;26(1):1-14. https://doi.org/1 $0.1111 /$ den. 12183

21. Sakurai Y, Mori Y, Okamoto H, Nishimura A, Komura E, Araki T, et al. Acidinhibitory effects of vonoprazan $20 \mathrm{mg}$ compared with esomeprazole $20 \mathrm{mg}$ or rabeprazole $10 \mathrm{mg}$ in healthy adult male subjects - a randomized openlabel cross-over study. Aliment Pharmacol Ther. 2015;42(6):719-30. https:// doi.org/10.1111/apt.13325

22. Tsuchiya I, Kato Y, Tanida E, Masui Y, Kato S, Nakajima A, et al. Effect of vonoprazan on the treatment of artificial gastric ulcers after endoscopic submucosal dissection: prospective randomized controlled trial. Dig Endosc. 2017;29(5):576-83. https://doi.org/10.1111/den.12857.

23. Koh R, Hirasawa $K$, Yahara S, Oka H, Sugimori K, Morimoto M, et al. Antithrombic drugs are risk factors for delayed postoperative bleeding after endoscopic submucosal dissection for gastric neoplasms. Gastrointest Endosc. 2013;78(3):476-83. https://doi.org/10.1016/j.gie.2013.03.008.

24. Libânio D, Costa MN, Pimentel-Nunes P, Dinis-Ribeiro M. Risk factors for bleeding after gastric endoscopic submucosal dissection: a systematic review and meta-analysis. Gastrointest Endosc. 2016;84(4):572-86. https:// doi.org/10.1016/j.gie.2016.06.033.

25. Kawata N, Ono H, Takizawa K, Kakushima N, Tanaka M, Igarashi K, et al. Efficacy of polyglycolic acid sheets and fibrin glue for prevention of bleeding after gastric endoscopic submucosal dissection in patients under continued antithrombotic agents. Gastric Cancer. 2018;21(4):696-702. https://doi.org/10.1007/s10120-018-0791-4

26. Goto M, Oyama T, Ono H, Takahashi A, Fujishiro M, et al. Endoscopic handsuturing is feasible, safe, and may reduce bleeding risk after gastric endoscopic submucosal dissection: a multicenter pilot study. Gastrointest Endosc. 2020;91(5):1195-202. https://doi.org/10.1016/j.gie.2019.12.046.

27. Guo WQ, Chen XH, Tian XY, Li L. Differences in gastrointestinal safety profiles among novel oral anticoagulants: evidence from a network metaanalysis. Clin Epidemiol. 2019;11:911-21. https://doi.org/10.2147/CLEP.S21 9335

\section{Publisher's Note}

Springer Nature remains neutral with regard to jurisdictional claims in published maps and institutional affiliations.

Ready to submit your research? Choose BMC and benefit from:

- fast, convenient online submission

- thorough peer review by experienced researchers in your field

- rapid publication on acceptance

- support for research data, including large and complex data types

- gold Open Access which fosters wider collaboration and increased citations

- maximum visibility for your research: over $100 \mathrm{M}$ website views per year

At $\mathrm{BMC}$, research is always in progress.

Learn more biomedcentral.com/submissions 